\title{
Molecular and catalytic properties of fungal extracellular cellobiose dehydrogenase produced in prokaryotic and eukaryotic expression systems
}

\author{
Su Ma', Marita Preims ${ }^{1}$, François Piumi ${ }^{1}$, Lisa Kappel ${ }^{3}$, Bernhard Seiboth ${ }^{3}$, Eric Record ${ }^{4}$, Daniel Kracher ${ }^{1}$ \\ and Roland Ludwig ${ }^{1 *}$ (D)
}

\begin{abstract}
Background: Cellobiose dehydrogenase $(\mathrm{CDH})$ is an extracellular enzyme produced by lignocellulolytic fungi. cdh gene expression is high in cellulose containing media, but relatively low $\mathrm{CDH}$ concentrations are found in the supernatant of fungal cultures due to strong binding to cellulose. Therefore, heterologous expression of CDH in Pichia pastoris was employed in the last 15 years, but the obtained enzymes were over glycosylated and had a reduced specific activity.
\end{abstract}

Results: We compare the well-established CDH expression host P. pastoris with the less frequently used hosts Escherichia coli, Aspergillus niger, and Trichoderma reesei. The study evaluates the produced quantity and protein homogeneity of Corynascus thermophilus CDH in the culture supernatants, the purification, and finally compares the enzymes in regard to cofactor loading, glycosylation, catalytic constants and thermostability.

Conclusions: Whereas E. coli could only express the catalytic dehydrogenase domain of CDH, all eukaryotic hosts could express full length $\mathrm{CDH}$ including the cytochrome domain. The $\mathrm{CDH}$ produced by T. reesei was most similar to the $\mathrm{CDH}$ originally isolated from the fungus $\mathrm{C}$. thermophilus in regard to glycosylation, cofactor loading and catalytic constants. Under the tested experimental conditions the fungal expression hosts produce CDH of superior quality and uniformity compared to P. pastoris.

Keywords: Aspergillus niger, Cellobiose dehydrogenase, Cofactor loading, Escherichia coli, Glycoforms, Heterologous expression, Pichia pastoris, Trichoderma reesei

\section{Background}

Cellobiose dehydrogenase (CDH, EC 1.1.99.18, CAZy AA 3.1) is an extracellular flavocytochrome produced by a number of wood degrading fungi, when cellulosic materials are utilized as carbon source [1]. Recent studies showed that the physiological function of $\mathrm{CDH}$ is the donation of electrons to copper-dependent lytic

\footnotetext{
*Correspondence: roland.ludwig@boku.ac.at

${ }^{1}$ Department of Food Sciences and Technology, Vienna Institute of Biotechnology, BOKU-University of Natural Resources and Life Sciences, Vienna, Austria

Full list of author information is available at the end of the article
}

polysaccharide monooxygenase (LPMO) $[2,3]$. This oxidative $\mathrm{CDH} / \mathrm{LPMO}$ system enhances the degradation rate of crystalline cellulose, and is widespread throughout the fungal kingdom together with the well-known hydrolytic cellulases $[4,5]$. $\mathrm{CDH}$ is a monomeric enzyme that belongs to the glucose-methanol-choline (GMC) family of oxidoreductases [6]. It is composed of a large catalytic flavodehydrogenase domain $(\mathrm{DH})$ containing one noncovalently bound flavin adenine dinucleotide (FAD). DH is connected to an electron transferring haem $b$-containing cytochrome domain (CYT) by a long, flexible linker enriched in hydroxy amino acids [7]. Recently reported crystal and solution structures of $\mathrm{CDH}$ demonstrated a 
dynamic interaction between DH and CYT. CYT acts as a mobile domain that reduces the active site copper of LPMO [7]. This intricate structure makes $\mathrm{CDH}$ a difficult enzyme to produce. A phylogenetic analysis of $\mathrm{CDH}$ sequences from various fungal sources showed a division of the enzymes into three distinct classes: class I represents only basidiomycetous $\mathrm{CDHs}$, which are shorter in sequence and have a highly conserved linker sequence [8]; class II exclusively comprises the more complex ascomycetous CDHs, either with or without a type- 1 carbohydrate-binding module, corresponding to classes IIA and IIB, respectively. Class III contains a different branch of so far uncharacterized CDHs [9]. Due to its electron transferring properties, $\mathrm{CDH}$ has been widely recognized as a versatile biorecognition element in electrochemical biosensors, which is capable of detecting a wide variety of carbohydrates (cellobiose, cellodextrins, lactose, maltose, glucose) as well as quinones and catecholamines [10,11]. This ability is also exploited for the development of $\mathrm{CDH}$ based anodes in enzymatic biofuel cells [12]. Because of the high interest in this oxidoreductase, high quality preparations of $\mathrm{CDHs}$ are requested in large quantities.

The production of $\mathrm{CDHs}$ by lignocellulose-degrading fungi results in reasonable amounts, especially in media containing pure cellulose [13]. However, the cellulosebinding ability of $\mathrm{CDH}$ results in a relatively low enzyme concentration in the supernatant, which makes the protein purification from fungal cultures difficult and timeconsuming. Therefore, several $c d h$ genes have been cloned and recombinantly expressed [14-16]. Recombinant protein production allows a fast, reliable and efficient enzyme production and the possibility to generate genetically engineered enzymes. Escherichia coli is one of the most commonly used industrial microorganisms, but the recombinant production of intact $\mathrm{CDH}$ has not been achieved for this host so far. Like other secreted eukaryotic proteins, $\mathrm{CDH}$ is subjected to posttranslational modifications that affect the properties of the mature protein significantly [17]. These posttranslational modifications, such as $\mathrm{O}$ - and N-linked glycosylation, are not introduced by E. coli. Only the DH domain of Phanerochaete chrysosporium was reported to be functionally expressed in $E$. coli [18]. The produced activity after cell lysis was $733 \mathrm{U} \mathrm{L}^{-1}$ and the enzyme was purified to a specific activity of $16.7 \mathrm{U} \mathrm{mg}^{-1}$ with a yield of $7.3 \%$. Pichia pastoris has been used as a heterologous expression host for several basidiomycetous and ascomycetous $\mathrm{CDHs}[8,14$, 15, 19-21]. It typically achieves high expression levels, and well established strategies for large-scale production and easy genetic manipulation are available. The yeast performs basic eukaryotic post-translational modifications and typically secretes high amounts of functional enzymes. High expression levels were achieved for most CDHs produced by P. pastoris. In case of Pycnoporus cinnabarinus $\mathrm{CDH}, 7800 \mathrm{U} \mathrm{L}^{-1}\left(351 \mathrm{mg} \mathrm{L}^{-1}\right)$ were measured in the culture supernatant [14]. It was, however, observed that $\mathrm{CDHs}$ produced by their natural hosts have a higher specific activity than CDHs recombinantly produced in $P$. pastoris. The specific activity, and consequently the turnover number, of recombinant $\mathrm{CDH}$ from Corynascus thermophilus (CtCDH) was 5-times lower than observed for the enzyme isolated from the fungus [15]. This discrepancy was caused by a sub-stoichiometric occupation of catalytic sites with the FAD cofactor. Furthermore, recombinant CDHs produced by P. pastoris are typically over- or hyper-glycosylated, which might affect the essential intramolecular electron transfer reaction. To avoid these shortcomings, an expression host more closely related to fungal $\mathrm{CDH}$ producers would be of advantage. Nowadays, filamentous fungi are also well developed as expression hosts that are able to secrete large amounts of target proteins [22]. The development of new molecular genetic tools facilitates the usage of fungi in protein production [23], although only a limited number of fungal species have been explored so far, such as Aspergillus niger, A. oryzae or Trichoderma reesei. To date, two CDHs have been recombinantly produced in A. oryzae [24] and two in A. niger [16]. Maximal CDH activity reached $7620 \mathrm{U} \mathrm{L}^{-1}$ for the basidiomycetous Coprinopsis cinerea $\mathrm{CDH}$, whereas only $126 \mathrm{U} \mathrm{L}^{-1}$ were measured for the ascomycetous Podospora anserina CDH [16]. However, the quality of the recombinant enzyme in comparison to $P$. pastoris derived $\mathrm{CDH}$ cannot be judged due to the limited information. Wang and Lu heterologously expressed the $c d h$ gene from $P$. chrysosporium in T. reesei to study the synergism between $\mathrm{CDH}$ and cellulases [25]. But there is no further data of enzyme production or enzyme characterization. In order to identify the best expression host for high quality recombinant $\mathrm{CDH}$, a detailed comparison of enzymes produced by the different expression hosts is required.

It was the objective of this study to compare four expression systems in regard to their recombinantly produced DH/CDH from Corynascus thermophilus $(C t \mathrm{CDH})$. The prokaryotic expression system E. coli was explored to recombinantly produce the catalytic dehydrogenase domain of $C t \mathrm{CDH}(C t \mathrm{DH})$. The intact, fulllength $C t \mathrm{CDH}$ was expressed in P. pastoris and in the two filamentous fungi $A$. niger and $T$. reesei. In order to achieve high productivity, all cultivations were carried out in a scalable bioreactor system. Finally, the recombinant enzymes were purified and their spectral properties, uniformity of glycosylation, kinetic constants and thermostability were compared. 


\section{Results}

Production of the CtDH domain in E. coli and chromatographic purification

Production of $C t \mathrm{DH}$ was carried out in a 7 -L bioreactor. In order to increase protein solubility, the operating temperature was reduced from 30 to $25^{\circ} \mathrm{C}$ at an $\mathrm{OD}_{600}$ of 0.65 . The fermentation was stopped after $28 \mathrm{~h}$ when the specific activity started to decline. The highest volumetric activity obtained was $648 \mathrm{U} \mathrm{L}^{-1}$ (Fig. 1a) with a corresponding specific activity of $0.42 \mathrm{U} \mathrm{mg}^{-1}$. Approx. $1.5 \%$ $(\mathrm{w} / \mathrm{w})$ of the total proteins in the cell lysate accounted for $\mathrm{Ct} \mathrm{DH}$.

The fermentation broth was harvested at a wet biomass concentration of approx. $4800 \mathrm{~g} \mathrm{~L}^{-1}$ and was disrupted using a homogenizer. After a one-step chromatographic purification, electrophoretic analysis showed that three major bands at approximately 53, 25 and $12 \mathrm{kDa}$ were present (Additional file 1: Figure S1). Separation of these proteins was achieved by an ultrafiltration step. $C t \mathrm{DH}$ with a molecular mass of $53 \mathrm{kDa}$ was purified to homogeneity at a yield of $60 \%$ and had a specific activity of 27.5 $\mathrm{U} \mathrm{mg}^{-1}$ (Table 1). A summary of the purification procedures is presented in Additional file 1: Table S1. After purification, a bright-yellow protein solution typical for flavoproteins was obtained.

\section{Production of $\mathrm{CtCDH}$ in P. pastoris and purification}

Production of $C t C D H$ in $P$. pastoris was carried out in a 7-L bioreactor according to a previously published protocol [15]. The volumetric $\mathrm{CDH}$ activity in the culture supernatant reached 376 and $320 \mathrm{U} \mathrm{L}^{-1}$ when measured with the DCIP assay and the cyt $c$ assay, respectively. The recombinant $\mathrm{CDH}$ constituted up to $14 \%$ of the total proteins in the fermentation broth. $\mathrm{CtCDH}$ with an average molecular mass of $94 \mathrm{kDa}$ was purified to homogeneity resulting in a specific activity of $9.4 \mathrm{U} \mathrm{mg}^{-1}$ (DCIP assay) and $3.5 \mathrm{U} \mathrm{mg}^{-1}$ (cyt $c$ assay) at a final yield of $71 \%$.

\section{Production of $\mathrm{CtCDH}$ in $\mathrm{A}$. niger and purification}

Transformants were selected for their ability to grow on minimal medium plates without uridine. Approximately 100 uridine prototrophic transformants were obtained per microgram of expression vector and $24 \%$ of the obtained transformants showed $\mathrm{CDH}$ activity in the extracellular media after 10 days of cultivation.

The transformant with the highest $\mathrm{Ct} C \mathrm{CDH}$ production was selected for further experiments. Production was carried out in a 7-L bioreactor with $4 \mathrm{~L}$ of $A$. niger culture medium inoculated with $8 \times 10^{8}$ asexual spores. The glucose concentration dropped below the measurable concentration after the first 3 days and fast growth of $A$. niger mycelium was observed before day 3. $\mathrm{CDH}$ activity increased gradually from day 3 to day 9 , and then reached its peak activity. The culture supernatant showed a volumetric activity of $49 \mathrm{U} \mathrm{L}^{-1}$ with the DCIP assay and $21 \mathrm{U} \mathrm{L}^{-1}$ with the cyt $c$ assay at day 10 (Fig. 1b). The specific activity of the fermentation broth prior to purification was $0.44 \mathrm{U} \mathrm{mg}^{-1}$ with the DCIP assay and $0.19 \mathrm{U} \mathrm{mg}^{-1}$ with the cyt $c$ assay. The recombinant $\mathrm{CDH}$ made up $3.5 \%$ of the total protein mass in the fermentation broth.

The recombinant enzyme was purified to homogeneity using a two-step purification protocol employing hydrophobic interaction chromatography and anion exchange chromatography. The purity of $\mathrm{CtCDH}$ increased 52 -fold and the final purification yield was $54 \%$. The specific activity of the homogeneous enzyme was $14.1 \mathrm{U} \mathrm{mg}^{-1}$ with the DCIP assay and $11.1 \mathrm{U} \mathrm{mg}^{-1}$ with the cyt $c$ assay.

\section{Production of $\mathrm{CtCDH}$ in $\mathrm{T}$. reesei and purification}

Transformants were selected based on hygromycin resistance and purified to uninuclear clones through a singlespore culture. Twenty transformants that grew well on hygromycin plates were selected for $\mathrm{CDH}$ expression in shaking flask cultures. To scale-up enzyme production, the highest producing clone of $T$. reese $i$ was cultivated in a 2-L bioreactor. The glucose concentration decreased by $80 \%$ after the first day of incubation. The CDH activity increased rapidly from day 4 to 6 , when full depletion of glucose was observed. The peak activity reached $715 \mathrm{U} \mathrm{L}^{-1}$ with the DCIP assay and $362 \mathrm{U} \mathrm{L}^{-1}$ with the cyt $c$ assay (Fig. 1c). No further increase of $\mathrm{CDH}$ activity was observed from day 6 to 12, which suggests that the expression stopped at day 6 due to lack of glucose. The $\mathrm{Ct} \mathrm{CDH}$ concentration in the crude supernatant reached $29 \mathrm{mg} \mathrm{L}^{-1}$ based on the specific activity of the purified enzyme.

The recombinant $\mathrm{Ct} \mathrm{CDH}$ expressed in $T$. reesei was purified to apparent homogeneity as described for $A$. niger, and resulted in a 3.4-fold purification with a yield of $58 \%$ (Table 1). The already high specific activity of the culture supernatant $\left(3.7 \mathrm{U} \mathrm{mg}^{-1}\right)$ indicates that the recombinant $\mathrm{CtCDH}$ is the main secreted protein $(30 \%)$ in the $T$. reesei fermentation broth. The specific activity of the homogeneous enzyme was $14.3 \mathrm{U} \mathrm{mg}^{-1}$ with the DCIP assay and $12.5 \mathrm{U} \mathrm{mg}^{-1}$ with the cyt $c$ assay.

\section{Characterization of recombinant $\mathrm{CtDH}$ and $\mathrm{CtCDHs}$ Molecular properties}

Molecular masses of all recombinant enzymes were determined by SDS-PAGE (Fig. 2). The CtCDH expressed in $P$. pastoris showed a broad and diffuse band between 80 and $98 \mathrm{kDa}$, which was likely caused by heterogeneous glycosylation and the smearing of glycoproteins on SDS-PAGE gels, whereas the $C t C D H$ expressed in $A$. niger showed a smaller and sharper band (82 $\pm 2 \mathrm{kDa})$. 

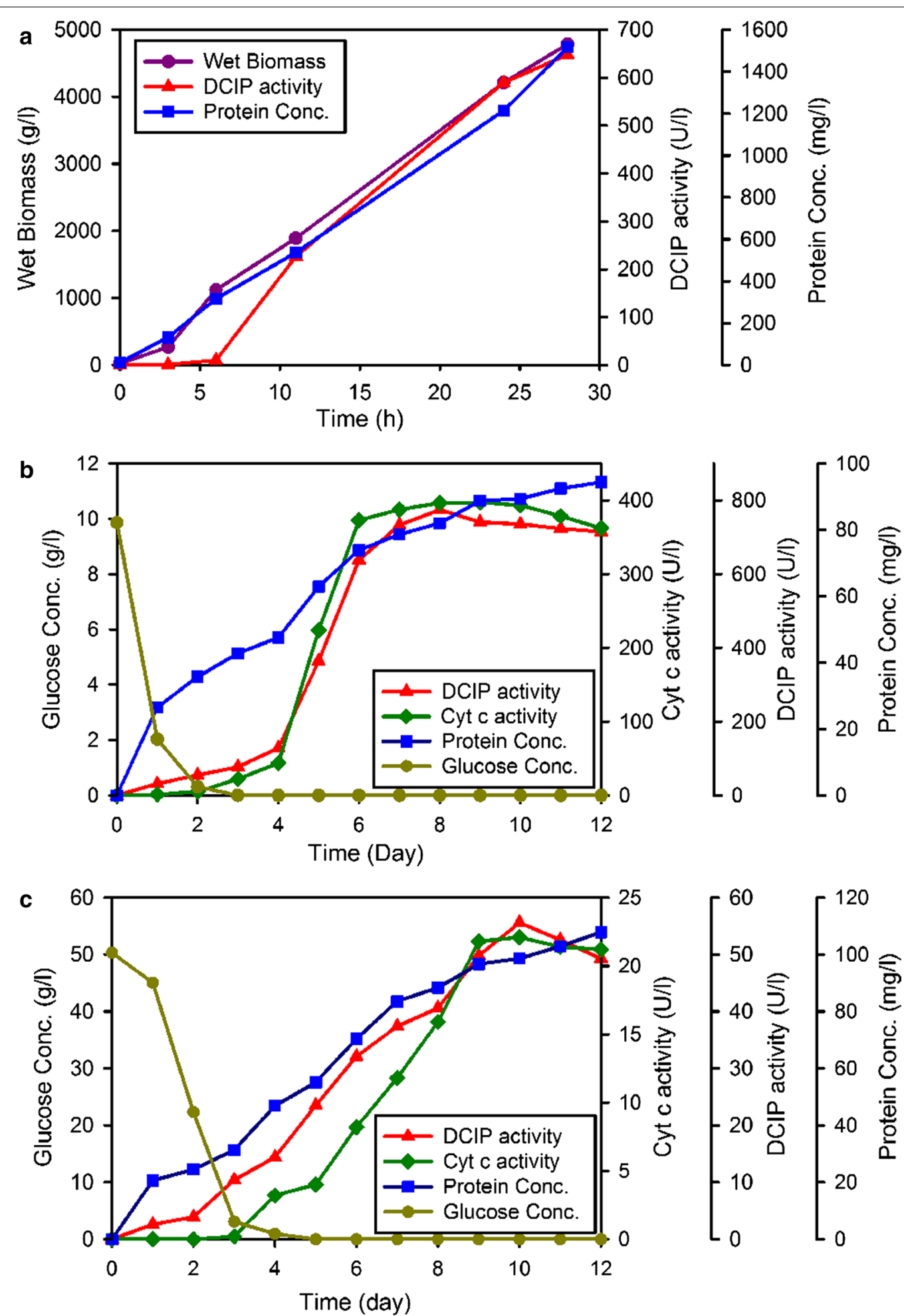

Fig. 1 Production of $\mathrm{CtDH} / \mathrm{CtCDH}$ s expressed in E. coli (a), A. niger $(\mathbf{b})$ and T. reesei (c). Purple circles wet biomass; red triangles volumetric activity (DCIP assay at acetate buffer pH 5.5), green diamonds volumetric activity (cyt $c$ assay in Tris/HCl buffer, $\mathrm{pH}$ 7.5), blue squares protein concentration (per broth volume), dark yellow circles glucose concentration of fermentation broth. The measurements were done in triplicates; the difference between the values was less than $5 \%$ 
Table 1 Comparison of enzyme production and purification for the four expression hosts

\begin{tabular}{|c|c|c|c|c|c|}
\hline $\mathrm{DH} / \mathrm{CDH}$ expressed by & E. coli & P. pastoris [15] & A. niger & & T. reesei \\
\hline \multicolumn{6}{|l|}{ Enzyme production } \\
\hline Cultivation time (h) & 28 & 111 & 288 & & 288 \\
\hline Wet cell mass $\left(\mathrm{g} \mathrm{L}^{-1}\right)$ & $4785 \pm 160$ & 275 & n.d. & & n.d. \\
\hline Soluble protein conc. $\left(\mathrm{mg} \mathrm{L}^{-1}\right)$ & $1517 \pm 44^{\mathrm{a}}$ & 633 & $108 \pm 4$ & & $94 \pm 3$ \\
\hline DCIP activity $\left(U L^{-1}\right)$ & $648 \pm 19$ & 376 & $49 \pm 2$ & & $715 \pm 14$ \\
\hline Cyt c activity $\left(\mathrm{UL}^{-1}\right)$ & - & 320 & $21 \pm 1$ & & $362 \pm 11$ \\
\hline DH/CDH expressed by & E. coli & P. pastoris & A. niger & T. reesei & \\
\hline \multicolumn{6}{|l|}{ Enzyme purification } \\
\hline Purification steps & IMAC & $\begin{array}{l}\text { Phenyl Sepharose and } \\
\text { QSource }\end{array}$ & $\begin{array}{l}\text { Phenyl Sepharose and } \\
\text { QSource }\end{array}$ & \multicolumn{2}{|c|}{$\begin{array}{l}\text { Phenyl Sepharose and } \\
\text { QSource }\end{array}$} \\
\hline Purification yield (\%) & 60 & 71 & 54 & \multicolumn{2}{|l|}{58} \\
\hline Purification (fold) & 65.5 & 7.7 & 51.8 & \multicolumn{2}{|l|}{3.4} \\
\hline Specific activity for DCIP $\left(\cup \mathrm{mg}^{-1}\right)$ & $27.5 \pm 0.3$ & $9.4 \pm 0.2$ & $14.1 \pm 0.1$ & \multicolumn{2}{|l|}{$14.3 \pm 0.1$} \\
\hline Specific activity for cyt c $\left(\cup \mathrm{mg}^{-1}\right)$ & - & $3.5 \pm 0.1$ & $11.1 \pm 0.2$ & \multicolumn{2}{|l|}{$12.5 \pm 0.2$} \\
\hline FAD loading (\%) & $52 \pm 2$ & $44 \pm 1$ & $56 \pm 1$ & \multicolumn{2}{|l|}{$68 \pm 3$} \\
\hline Glycosylation (\%) & 0 & $18.9 \pm 12.1$ & $9.4 \pm 2.7$ & \multicolumn{2}{|l|}{$1.4 \pm 1.3$} \\
\hline
\end{tabular}

The measurements were done in triplicates

n.d. not determined, - the $\mathrm{DH}$ domain has no cyt $c$ activity

a Intracellular protein

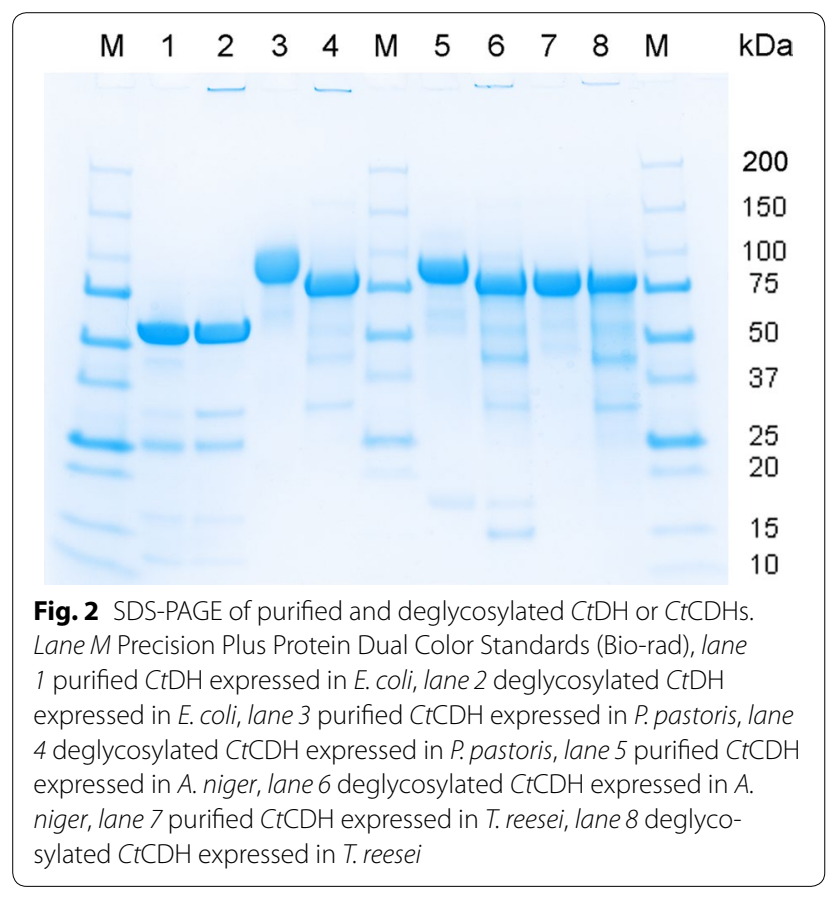

The $\mathrm{CtCDH}$ expressed in $T$. reesei showed the sharpest band with a molecular mass of $76 \pm 1 \mathrm{kDa}$, indicating little glycosylation and a low heterogeneity of the protein. After deglycosylation under denaturing conditions with PNGase F, single sharp bands with an identical molecular mass of $75 \mathrm{kDa}$ were found for all CDHs. The
$C t \mathrm{DH}$ expressed in $E$. coli, before and after deglycosylation, showed identical bands with a molecular weight of $53 \mathrm{kDa}$. The additional bands at $35 \mathrm{kDa}$ in the deglycosylated samples originate from PNGase F.

The UV/Vis spectrum of the purified $C t D H$ (Fig. 3a) is characteristic for a flavoprotein. The FAD cofactor has an absorption spectrum with a maximum at $450 \mathrm{~nm}$ and a wide shoulder in the region of $360 \mathrm{~nm}$. The FAD spectra of full-length CDHs are partially overlaid by the haem $b$ absorbance. The spectra of all purified $C t C D H s$ (Fig. 3b-d) show the typical characteristics of a flavocytochrome. The major peak of the oxidised spectrum at $420 \mathrm{~nm}$ is the Soret peak of the haem cofactor, whereas the broad shoulder between 450 and $500 \mathrm{~nm}$ is mainly attributed to the FAD cofactor. Upon reduction of $C t \mathrm{CDH}$ by its native substrate cellobiose, peaks appeared at 429,533 , and $564 \mathrm{~nm}$, representing the Soret-, $\beta$ - and $\alpha$-peaks of the reduced haem. In this state, the absorption in the region between 450 and $500 \mathrm{~nm}$ decreased due to reduction of the FAD. The $\mathrm{R}_{\mathrm{Z}}$ $\left(\mathrm{A}_{420} / \mathrm{A}_{280}\right)$ values for $C t \mathrm{CDH}$ expressed in P. pastoris, $A$. niger and T. reesei were $0.60,0.61$ and 0.61 , respectively, indicating the same, high purity. After protein precipitation with trichloroacetic acid [26], the amount of the released FAD was determined. We found that $52 \%$ of the active sites of the DH domain expressed in $E$. coli contained FAD and that the FAD loading of $C t \mathrm{CDH}$ expressed in P. pastoris, A. niger and T. reesei was 44, 56 and $68 \%$, respectively. 

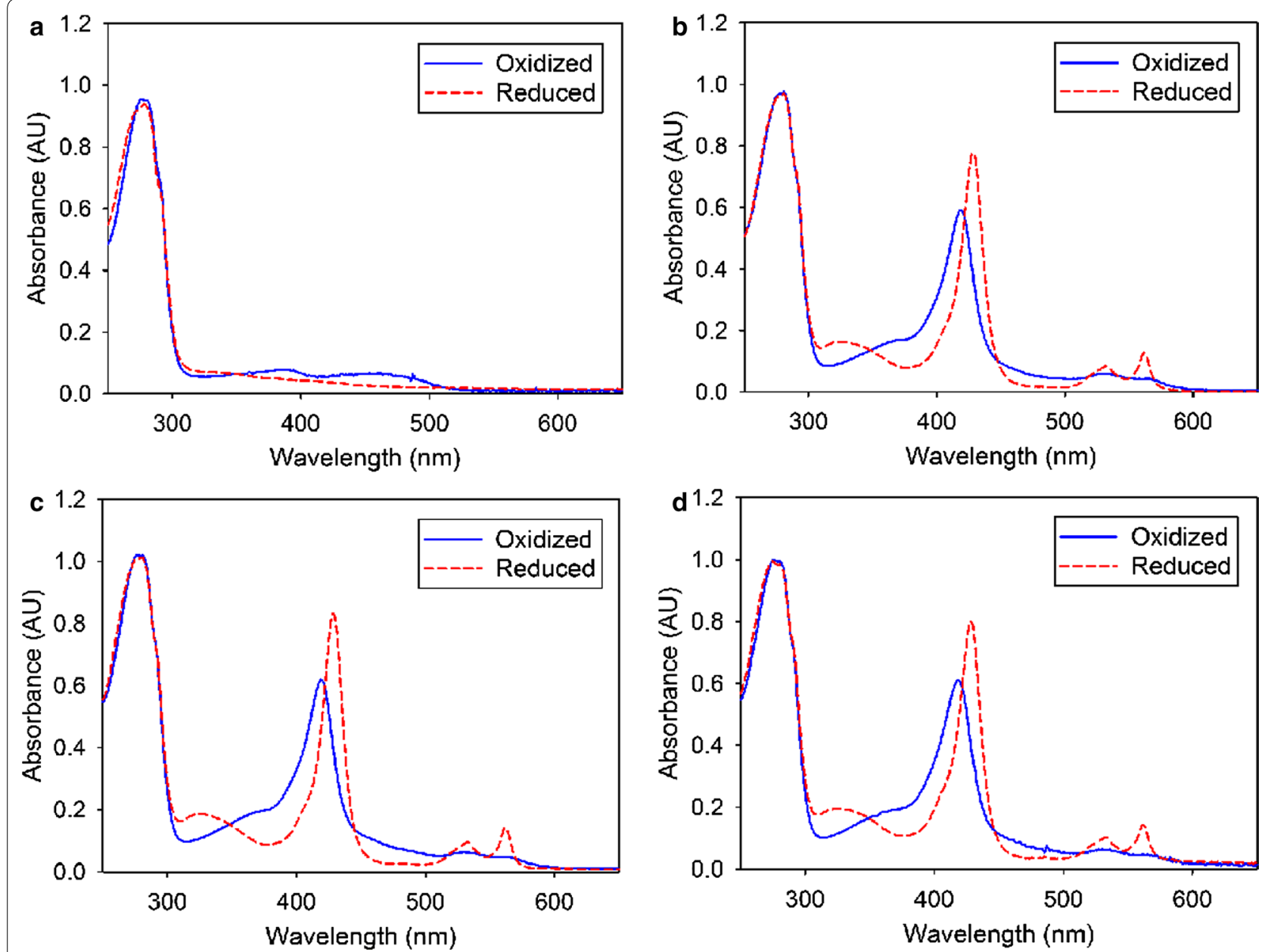

Fig. 3 Spectral characterization of $\mathrm{CtDH} / \mathrm{CtCDH}$ s showing the oxidized (blue line) and reduced (red dashes) spectra. Some grains of solid cellobiose were added to the cuvette and used for reduction. Spectra of CtDH or CtCDHs expressed in E. coli (a), P. pastoris (b), A. niger (c) and T. reesei (d) are shown

\section{Catalytic properties}

The catalytic constants for the reduction of the twoelectron acceptor DCIP were determined at $\mathrm{pH} 5.5$, whereas reduction of the one-electron acceptor cyt $c$ was determined at $\mathrm{pH} 7.5$ (Table 2). The $\mathrm{K}_{\mathrm{M}}$ values for cellobiose were similar for all enzymes, and were found to be around $362 \mu \mathrm{M}$ measured with DCIP as electron acceptor and $100 \mu \mathrm{M}$ using cyt $c$ as electron acceptor. In contrast to the almost identical $K_{M}$ values, a systematic difference of the $k_{\text {cat }}$ values among the $C t \mathrm{DH}$ and the three $C t C D H s$ was observed. The $C t \mathrm{DH}$ expressed in $E$. coli had the highest $k_{\text {cat }}$ value $\left(15.5 \mathrm{~s}^{-1}\right)$ for DCIP. $C t \mathrm{CDH}$ expressed by the eukaryotic hosts $T$. reesei and A. niger showed also high $k_{\text {cat }}$ values of 15.2 and $13.3 \mathrm{~s}^{-1}$,
Table 2 Comparison of steady-state kinetic constants of CtDH and CtCDHs for cellobiose

\begin{tabular}{lcrl}
\hline Enzyme & $\mathbf{K}_{\mathbf{M}}(\boldsymbol{\mu} \mathbf{M})$ & $\boldsymbol{k}_{\text {cat }}\left(\mathbf{s}^{-\mathbf{1}}\right)$ & $\boldsymbol{k}_{\text {cat }} / \mathbf{K}_{\mathbf{M}}\left(\mathbf{m M}^{-\mathbf{1}} \mathbf{s}^{-\mathbf{1}}\right)$ \\
\hline DCIP assay & & & \\
E. coli (DH) & $367 \pm 11$ & $15.5 \pm 0.2$ & 42 \\
P. pastoris (CDH) & $373 \pm 14$ & $8.1 \pm 0.3$ & 22 \\
A. niger (CDH) & $357 \pm 18$ & $13.3 \pm 0.3$ & 37 \\
T. reesei (CDH) & $349 \pm 21$ & $15.2 \pm 0.4$ & 44 \\
Cyt c assay & & & \\
P. pastoris (CDH) & $81 \pm 7$ & $2.6 \pm 0.1$ & 32 \\
A. niger (CDH) & $102 \pm 5$ & $7.6 \pm 0.2$ & 74 \\
T. reesei (CDH) & $118 \pm 11$ & $7.9 \pm 0.2$ & 67 \\
\hline
\end{tabular}

The measurements were done in triplicates 
respectively, but $C t \mathrm{CDH}$ expressed in $P$. pastoris had a twofold lower $k_{\text {cat }}$. The cyt $c$ activity for both filamentous fungal expression systems was equally good, resulting in $k_{\text {cat }}$ values of 7.6 and $7.9 \mathrm{~s}^{-1}$. For P. pastoris the turnover number was 3 times lower.

\section{Thermostability}

The thermostability of $\mathrm{CtDH}$ and $\mathrm{CtCDHs}$ was determined using the ThermoFAD method [27] and the intrinsic tryptophan fluorescence upon protein unfolding. All enzymes showed transition midpoint temperatures $\left(\mathrm{T}_{\mathrm{m}}\right)$ in a narrow temperature range of $58.1 \pm 1.5^{\circ} \mathrm{C} . \mathrm{T}_{\mathrm{m}}$ values obtained with the ThermoFAD method were generally higher by $1-1.5{ }^{\circ} \mathrm{C}$ than $\mathrm{T}_{\mathrm{m}}$ values obtained from tryptophan fluorescence (Table 3; Additional file 1: Figure S2). The $\mathrm{T}_{\mathrm{m}}$ values for $C t \mathrm{CDH}$ expressed in P. pastoris and $A$. niger were slightly higher than those for $C t C D H$ expressed in E. coli and T. reesei. This was observed with both methods. Protein precipitation occurred at the end of the unfolding experiments in case of the nonglycosylated $C t \mathrm{DH}$ and the less glycosylated $C t \mathrm{CDHs}$ expressed by $A$. niger and $T$. reesei.

\section{Discussion}

This study compared the suitability of four different expression systems for the production of $\mathrm{CDH}$. We evaluated the titer of secreted $\mathrm{CDH}$, the purification procedure and yield together with the molecular and kinetic properties of the purified, recombinant enzymes. The prokaryotic expression host $E$. coli can express only the $\mathrm{DH}$ domain of $\mathrm{CtCDH}$, but produced a high amount of it in a much shorter time $(28 \mathrm{~h})$ than the tested eukaryotic expression systems. Per liter of fermentation medium $652 \mathrm{U}$ of $\mathrm{CDH}$ activity were obtained, which is 1.7 -fold higher than the previously reported amount of the $\mathrm{DH}$ domain from Phanerochaete chrysosporium (PcDH) expressed in E. coli [18].

The full-length $\mathrm{CDH}$, comprising both $\mathrm{CYT}$ and $\mathrm{DH}$, could so far only be functionally expressed in eukaryotic expression hosts. Several CDHs have been successfully expressed in the methylotrophic yeast $P$. pastoris,

Table 3 Transition midpoint temperatures $\left(T_{\mathrm{m}}\right)$ measured with the ThermoFAD method and the intrinsic tryptophan fluorescence

\begin{tabular}{lll}
\hline Enzyme & ThermoFAD & Trp unfolding \\
\hline E. coli $(\mathrm{DH})$ & $57.7 \pm 0.3$ & $56.9 \pm 0.4$ \\
P. pastoris $(\mathrm{CDH})$ & $59.2 \pm 0.1$ & $57.4 \pm 0.6$ \\
A. niger $(\mathrm{CDH})$ & $59.7 \pm 0.1$ & $57.5 \pm 0.5$ \\
T. reesei $(\mathrm{CDH})$ & $57.8 \pm 0.2$ & $56.6 \pm 0.3$ \\
\hline
\end{tabular}

The measurements were done in triplicates including $\mathrm{Ct} \mathrm{CDH}$ [15]. The reported volumetric expression levels vary from 376 to $7800 \mathrm{U} \mathrm{L}^{-1}$, which can be recalculated to $\mathrm{CDH}$ concentrations between 79 and $351 \mathrm{mg} \mathrm{L}^{-1}$, respectively (Additional file 1: Table S2). Four $\mathrm{CDHs}$ have been expressed in the fungal expression hosts $A$. oryzae and $A$. niger [16, 24], with different expression levels. Additional file 1: Table S2 shows that basidiomycetous $\mathrm{CDHs}$ are generally expressed with higher volumetric activities than ascomycetous $\mathrm{CDHs}$, which typically have lower specific activities. In terms of produced $\mathrm{CDH}$ concentration, the expression levels between basidiomycetous and ascomycetous $\mathrm{CDHs}$ are comparable, but differences arising from diverse fermentation protocols are obvious. In this work, the production level of $C t \mathrm{CDH}$ in $A$. niger was very low $\left(55 \mathrm{U} \mathrm{L}^{-1}\right)$, which is in accordance with the reported data for other ascomycetous CDHs. This study reports also the first successful expression of $\mathrm{CtCDH}$ in $T$. reesei. The expression level of $800 \mathrm{U} \mathrm{L}^{-1}$ was the highest among the tested eukaryotic expression hosts in this study and compares well with other expression hosts in terms of secreted CDH concentration $\left(32 \mathrm{mg} \mathrm{L}^{-1}\right)$. Since $T$. reesei is known to produce high concentrations of recombinant proteins, an optimization of the fermentation protocol should further increase the $\mathrm{CDH}$ yield [29].

The specific CDH activity in the cell lysate or the culture supernatant differed among the expression hosts and influenced the purification strategy. The weight percentage of $C t \mathrm{DH}$ in the E. coli cell lysate was only $1.5 \%$ and a high amount of intracellular proteins was present. For easy purification of the $\mathrm{DH}$ domain it was necessary to fuse a C-terminal His-tag to the enzyme, which allowed a one-step purification via immobilized metal affinity chromatography and resulted in a much higher yield of $60 \%$ compared to only $2 \%$ for recombinant $P c \mathrm{DH}$ without His-tag [18]. Although E. coli is not able to introduce eukaryotic posttranslational modifications, the homogeneous $C t \mathrm{DH}$ exhibited a high specific activity of $27.5 \mathrm{U} \mathrm{mg}^{-1}$ using the DCIP assay.

Pichia pastoris is a well-established expression system which allows for a relatively high $\mathrm{CtCDH}$ production (15\% of total protein). However, the low cofactor occupancy and overglycosylation resulted in a $C t \mathrm{CDH}$ with a limited quality. The specific activity was $9.4 \mathrm{U} \mathrm{mg}^{-1}$ for DCIP and $5.3 \mathrm{U} \mathrm{mg}^{-1}$ for cyt $c$. Fungal hosts are thus preferable for the expression of high quality $\mathrm{CtCDH}$. Homogenous $\mathrm{CtCDH}$ has a specific activity around $14 \mathrm{U} \mathrm{mg}^{-1}$ using the DCIP assay and $12 \mathrm{U} \mathrm{mg}^{-1}$ using the cyt $c$ assay, which is comparable to the enzyme expressed by the native host [15]. The newly employed expression host $T$. reesei showed the capability of secreting the mature $\mathrm{CtCDH}$ into the fermentation broth, which made up $30 \%$ of all proteins in the supernatant. A. niger 
gave a low expression level (3.5\%) for this ascomycetous $\mathrm{CDH}$. The purification strategy worked similarly efficient for all three eukaryotic expression systems, giving yields between 54 and $60 \%$.

Glycosylation is a common post-translational modification in extracellular fungal proteins. Presumably, all native $\mathrm{CDHs}$ contain glycan structures, although the degree of glycosylation varies significantly, from $2 \%$ [28] up to $15 \%$ [29] of the total CDH protein mass. However, the most commonly used expression host $P$. pastoris usually attaches high mannose structures as N-glycosides, which can make up for $10-48 \%$ of the total mass (Additional file 1: Table S2). Six predicted glycosylation sites are found for the intact $\mathrm{CtCDH}$ using NetNGlyc 1.0, of which five are surface exposed and located on the DH domain. Interestingly, three glycosylation sites are close to the linker connecting DH and CYT. In addition, there are eleven putative $\mathrm{O}$-glycosylation sites located on both domains (NetOGlyc 4.0). However the extent of O-glycosylation in native $\mathrm{CDHs}$ is uncertain. We conclude that the demand for highly active and uniform recombinant $\mathrm{CDH}$ preparations used for electrochemical and biocatalytic applications might be best served by CDH produced by T. reesei. SDS-PAGE indicated a very uniform glycosylation that makes up approx. $1.3 \%$ of the total protein mass. A higher percentage of glycosyl residues was observed for $C t \mathrm{CDH}$ expressed in A. niger (8\%) and the overglycosylation and heterogeneity of $\mathrm{CtCDH}$ produced in P. pastoris is least favorable in this respect (7-30\%).

Several sequence and structural factors have been proposed to contribute toward a greater stability of thermophilic proteins, such as the presence of prolines in loop regions or the stability of alpha-helix and surface salt bridges [30-32]. Glycosylation is another feature of eukaryotic proteins that frequently contributes to stability [33]. We compared the melting temperature of $C t \mathrm{DH}$ and all $\mathrm{CtCDHs}$ expressed in the study. Interestingly, neither the different FAD occupancy of the enzyme preparations nor their different degree of glycosylation influenced the overall thermostability. Using two methods, we showed that the $T_{m}$ values of all enzyme preparations were within $1.5{ }^{\circ} \mathrm{C}$, including the least flavinated CtCDH expressed in P. pastoris.

The presence of the FAD cofactor in the DH domain of $\mathrm{CDH}$ is crucial for the enzymatic activity and was reported as a limiting factor in P. pastoris expressed $\mathrm{CtCDH}$ [15]. In this work, the FAD loading of all four enzymes was experimentally measured and analyzed together with the catalytic turnover. For eukaryotic expression hosts, $C t \mathrm{CDH}$ expressed in $T$. reesei had the highest FAD loading (65\%) and gave the highest turnover number. In contrast, $\mathrm{CtCDH}$ expressed in P. pastoris showed the lowest specific activity and the lowest FAD content. The re-calculated $k_{\text {cat }}$ values (normalized by the FAD loading) are very similar $\left(21.5 \pm 2.8 \mathrm{~s}^{-1}\right)$, demonstrating that the FAD loading is the key factor for the catalytic capability of the DH domain. However, the recalculated $k_{\text {cat }}$ value of $C t \mathrm{DH}$ is higher $\left(29.8 \mathrm{~s}^{-1}\right)$, which could indicate that the substrate channel is more accessible in absence of the CYT domain.

The DCIP reduction rate depends only on the catalytic reaction in the DH domain, whereas the reduction of cyt $c$ is limited by the intramolecular electron transfer (IET) between DH and CYT. The cyt $c$ assay has been reported to give a good estimation of the IET rate, because the electron transfer between the cofactors is, compared to the catalytic turnover at the FAD, rate limiting. It is interesting to observe that overglycosylation of the $\mathrm{CDH}$ molecule reduces the IET rate. A decrease of the IET is visible from the 3-5 times lower $k_{c a t}$ values of cyt $c$ reduction for the highly glycosylated $C t \mathrm{CDH}$ expressed by $P$. pastoris and $A$. niger (Table 2). The $k_{\text {cat }}$ value of $C t C D H$ expressed in $A$. niger for cellobiose measured with the DCIP assay is about two times higher than for $\mathrm{CtCDH}$ expressed in $P$. pastoris whereas the $k_{c a t}$ value for cellobiose measured with the cyt $c$ assay is two times lower. This indicates that the $C t \mathrm{CDH}$ expressed in $A$. niger has a reduced IET rate. A comparison of the specific cyt $c$ activity of the recombinant $C t \mathrm{CDH}$ expressed by $T$. reesei with $C t \mathrm{CDH}$ produced by $C$. thermophilus show a similar value, but the specific activity for DCIP is only $40 \%$ compared to the published data [15]. These results suggest that for recombinant $\mathrm{CDH}$ expressed by fungal hosts, the FAD cofactor loading is a more important issue than glycosylation. An optimization of $\mathrm{CDH}$ expression in T. reesei seems to be the best starting point for future studies.

\section{Conclusions}

Escherichia coli is a good expression system to express the flavodehydrogenase domain of $\mathrm{CtCDH}$. It is easy to manipulate and fast producing. The $P$. pastoris expression system allows high protein yields, however, the low FAD loading and overglycosylation of $\mathrm{CDH}$ cause low specific activities. The fungal expression systems produced $\mathrm{Ct} \mathrm{CDH}$ of superior quality and uniformity. Under the tested experimental conditions, the production of $C t \mathrm{CDH}$ by $A$. niger results in lower amounts than $C t \mathrm{CDH}$ production by $T$. reesei, but both fungal expression systems could be further optimized towards increased productivity by optimizing promoters and expression conditions. In conclusion, T. reesei is the best expression system for recombinant $C t C D H$ production. The produced $C t \mathrm{CDH}$ has a high cofactor loading and the glycosylation and specific activity are closest to the $\mathrm{CDH}$ isolated from C. thermophilus. 


\section{Methods}

\section{Strains and media}

The chemically competent E. coli strains NEB $5 \alpha$ and T7 Express were purchased from New England Biolabs (New England BioLabs, Frankfurt, Germany). E. coli NEB $5 \alpha$ was used for vector construction and propagation. E. coli cells were grown at $37{ }^{\circ} \mathrm{C}$ in lysogeny broth (LB) or on LB agar supplemented with ampicillin $\left(100 \mathrm{mg} \mathrm{mL}^{-1}\right)$. MagicMedia E. coli expression medium (Thermo Fisher Scientific) was used for expression studies.

Pichia pastoris strain X-33 containing the published plasmid pPICctcdh was used for CtCDH expression [15]. $P$. pastoris cells were grown in yeast peptone dextrose (YPD) broth or on YPD plates with zeocin $\left(100 \mathrm{mg} \mathrm{L}^{-1}\right)$ at $30{ }^{\circ} \mathrm{C}$ and the Basal Salts Medium was used for fermentation.

Aspergillus niger strain D15\#26 (pyrG-) [34] was used for heterologous expression of the recombinant $\mathrm{CtCDH}$. After cotransformation with vectors containing the pyrG gene and the expression cassette (Fig. 4c), respectively, transformants of $A$. niger were selected at $30{ }^{\circ} \mathrm{C}$ on solid minimal medium (without uridine) containing $70 \mathrm{mM} \mathrm{NaNO}, 7 \mathrm{mM} \mathrm{KCl}, 11 \mathrm{mM} \mathrm{K \textrm {K } _ { 2 }} \mathrm{HPO}_{4}$, $2 \mathrm{mM} \mathrm{MgSO} 4$, and $1 \%(\mathrm{w} / \mathrm{v})$ glucose and trace elements $\left(1000 \times\right.$ stock; $76 \mathrm{mM} \mathrm{ZnSO}, 178 \mathrm{mM} \mathrm{H}_{3} \mathrm{BO}_{3}$, $25 \mathrm{mM} \mathrm{MnCl}_{2}, 18 \mathrm{mM} \mathrm{FeSO}_{4}, 7.1 \mathrm{mM} \mathrm{CoCl}_{2}, 6.4 \mathrm{mM}$ $\mathrm{CuSO}_{4}, 6.2 \mathrm{mM} \mathrm{Na} \mathrm{MoO}_{4}$, and $174 \mathrm{mM}$ EDTA). The best producing transformant for $\mathrm{CDH}$ expression was screened on culture medium containing $70 \mathrm{mM} \mathrm{NaNO}_{3}$, $7 \mathrm{mM} \mathrm{KCl}, 200 \mathrm{mM} \mathrm{Na}_{2} \mathrm{HPO}_{4}, 2 \mathrm{mM} \mathrm{MgSO}_{4}, 5 \%$ (w/v) glucose and trace elements at $\mathrm{pH} 5.5$ inoculating it with $2 \times 10^{6}$ spores $\mathrm{mL}^{-1}$. The same medium was used for fermentation.

Trichoderma reesei $\Delta x y r 1$ strain [35] was used for $\mathrm{CtCDH}$ expression. This strain derived from $T$. reese QM9414 (ATCC 26921) is deleted in the major cellulase and xylanase regulator which provides a (hemi)cellulase free background. It was maintained on potato dextrose agar (PDA) plates at $28{ }^{\circ} \mathrm{C}$. Transformants of $T$. reesei were grown for selection on PDA with hygromycin B $\left(50 \mathrm{mg} \mathrm{L}^{-1}\right)$. For $\mathrm{CtCDH}$ expression, strains were grown at $28^{\circ} \mathrm{C}$ in a modified MA-Medium (Mandels-Andreotti) [36] containing $10 \mathrm{~g} \mathrm{~L}^{-1}$ glucose, $1.4 \mathrm{~g} \mathrm{~L}^{-1}\left(\mathrm{NH}_{4}\right)_{2} \mathrm{SO}_{4}$, $2.0 \mathrm{~g} \mathrm{~L}^{-1} \mathrm{KH}_{2} \mathrm{PO}_{4}, 0.3 \mathrm{~g} \mathrm{~L}^{-1} \mathrm{MgSO}_{4} \cdot 7 \mathrm{H}_{2} \mathrm{O}, 0.4 \mathrm{~g} \mathrm{~L}^{-1}$ $\mathrm{CaCl}_{2} \cdot 2 \mathrm{H}_{2} \mathrm{O}, 1 \mathrm{~g} \mathrm{~L}^{-1}$ peptone, and $1 / 50(\mathrm{v} / \mathrm{v})$ of the trace element solution $\left(0.25 \mathrm{~g} \mathrm{~L}^{-1} \mathrm{FeSO}_{4} \cdot 7 \mathrm{H}_{2} \mathrm{O}, 0.08 \mathrm{~g} \mathrm{~L}^{-1}\right.$ $\mathrm{MnSO}_{4} \cdot \mathrm{H}_{2} \mathrm{O}, \quad 0.07 \mathrm{~g} \mathrm{~L}^{-1} \quad \mathrm{ZnSO}_{4} \cdot 7 \mathrm{H}_{2} \mathrm{O}, \quad 0.1 \mathrm{~g} \mathrm{~L}^{-1}$ $\left.\mathrm{CoCl}_{2} \cdot 2 \mathrm{H}_{2} \mathrm{O}\right)$ at $\mathrm{pH} 5.0$ inoculated with $10^{6}$ spores $\mathrm{mL}^{-1}$. The same medium was used for fermentation.

\section{Chemicals and vectors}

All chemicals were purchased from Sigma, Fluka, Roth or VWR and were of the highest purity available. Primers were synthesized by Microsynth and nucleotide

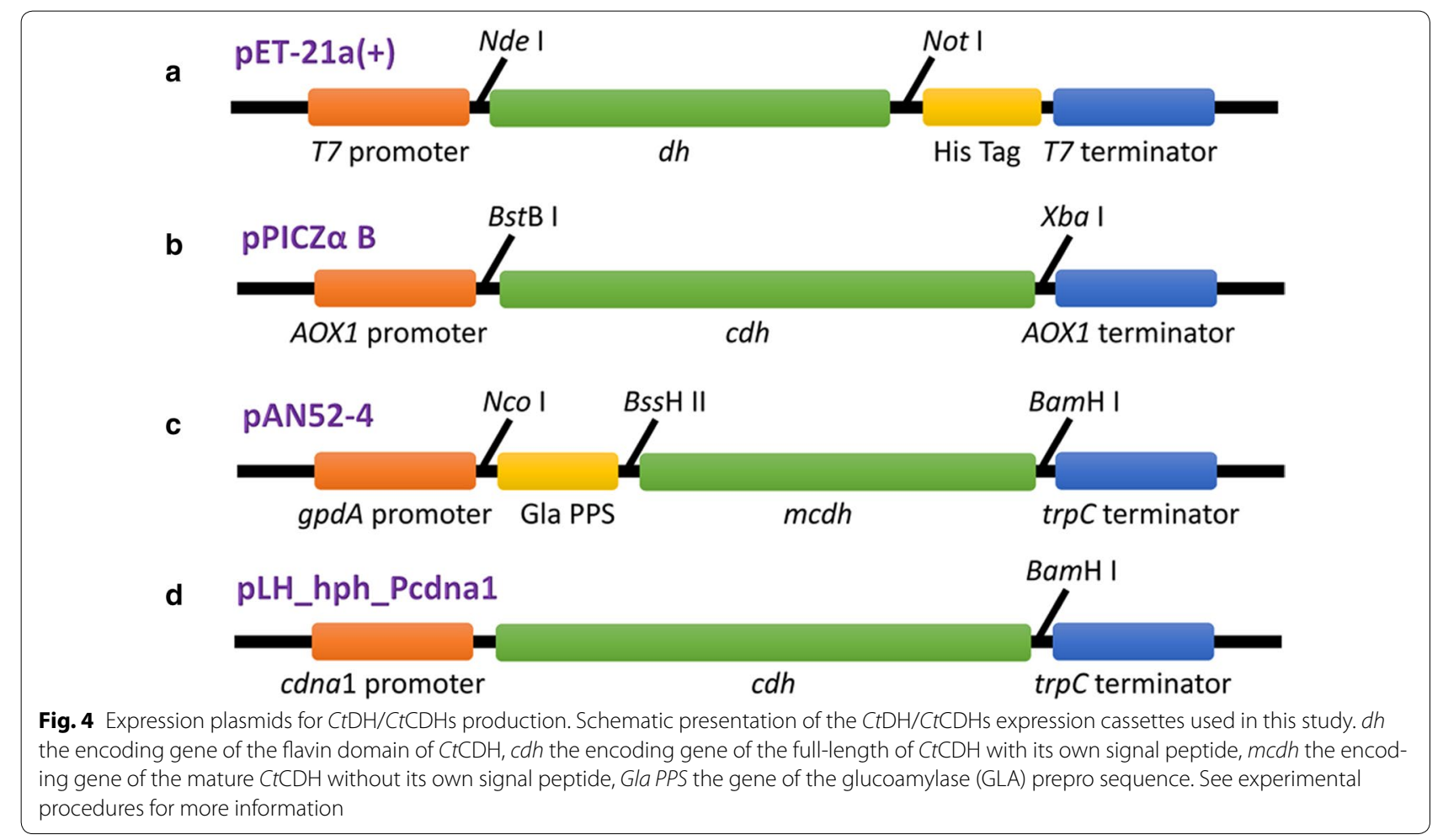


Table 4 Nucleotide sequences of primers used in this study

\begin{tabular}{ll}
\hline Primer name & Sequence (from $\mathbf{5}^{\prime}$ to $\mathbf{3}^{\prime}$ ) \\
\hline Pecoli-F1 & GGAATTCCATATGGACACGTATGATTACATCGT \\
Pecoli-R1 & ATAAGAATGCGGCCGCATAACGCAGGGACAGGATGC \\
Paniger-F1 & TTGGCGCGCTCAGATGACCGAAGGGACGTA \\
Paniger-R1 & CGGGATCCCTAATACCGCAGGGACAGGA \\
Ptreesei-F1 & TCATCGATGTCGACCATGAAGCTTCTCAGCCGCGTTG \\
Ptreesei-R1 & CGGGATCCCTAATACCGCAGGGACAGGATG \\
Ptrpc-F1 & CGGGATCCGAAGCTTGAGATCCAC \\
Ptrpc-R1 & CCAAGCTTGCATGCCAAGAAGGATTACCTCTAAACAAG \\
\hline
\end{tabular}

The underlined characters indicate the restriction site

sequences are shown in Table 4. Restriction enzymes, dNTP mix and T4 DNA ligase were from Fermentas and the Phusion polymerase from New England Biolabs. The plasmid pET-21a (+) from Novagen was used for expression in E. coli under control of the T7 promoter. For $C t \mathrm{CDH}$ expression in A. niger, pAN52-4 [37] and pAB4-1 [38] containing the pyrG selection marker were used. In expression vector pAN52-4, the $A$. niger constitutive gpdA promoter and the $A$. nidulans trp $C$ terminator were used to drive the expression of recombinant $C t C D H$. Vector pLH_hph_Pcdna1 [39] containing an hygromycin $B$ expression cassette as fungal selection marker followed by the constitutive $c d n a 1$ promoter region was used for CtCDH expression in T. reesei.

\section{Construction of the expression vectors}

The gene of the $\mathrm{CDH}$ flavin domain was PCR-amplified from pPICctcdh (Fig. 4b), a vector previously created to express the entire $\mathrm{CDH}$ in $P$. pastoris under the control of the AOX1 promoter [15]. Primers Pecoli-F1 and Pecoli-R1 (Table 4) were used to introduce the NdeI and NotI restriction sites, respectively. The PCR product was purified, digested and ligated into the $5^{\prime}-\mathrm{NdeI}$ and $3^{\prime}-\mathrm{Not} \mathrm{I}$ sites of pET-21a(+) in-frame with the six-histidine tag to generate plasmid pET21-CtDH (Fig. 4a).

The DNA fragment encoding the mature $\mathrm{Ct} C \mathrm{CDH}$ was amplified using primers Paniger-F1 and Paniger-R1 (Table 4). The amplicon was integrated into the pAN52-4 expression vector using a restriction cloning approach with BssHII and BamHI enzymes. In addition, the synthesized oligonucleotides of the glucoamylase (GLA) prepro sequence [40] was digested with $\mathrm{NcoI}$ and $\mathrm{Bss} \mathrm{HII}$ and ligated into the respective sites of pAN52-4 using the Rapid DNA Ligation Kit from Fermentas (Fig. 4c). The final construct pAN52-CtCDH was used to express $\mathrm{Ct} \mathrm{CDH}$ in $A$. niger.

The gene encoding the full-length $\mathrm{CDH}$ with its own signal peptide was PCR-amplified from pPICctcdh using primers Ptreesei-F1 and Ptreesei-R1 (Table 4). A
PCR-amplicon of the $A$. nidulans $\operatorname{trp} C$ terminator was digested by $\mathrm{BamHI}$ and ligated with the same predigested PCR product of $C t C D H$. The vector pLH_hph_Pcdna1 was linearized by $S b f l$ restriction enzyme and ligated with DNA fragment of $\mathrm{CtCDH}$ and TrpC terminator using In-Fusion HD Cloning Kits following the manufacturer's protocol (Takara Bio Europe, Saint-Germain-enLaye, France) (Fig. 4d). Correct insertion of the gene was checked by DNA sequencing.

\section{Selection of the production clones}

Correct insertion of the $C t \mathrm{DH}$ gene was checked by DNA sequencing and verified plasmid was transformed into $E$. coli T7 Express. The cells harboring pET21-CtDH were cultivated in small-scale with the auto-inducing MagicMedia to optimize the expression conditions. Baffled shaken flasks $(250 \mathrm{~mL})$ were filled with $78 \mathrm{~mL}$ MagicMedia and $2 \mathrm{~mL}$ of overnight seed culture (1:40 dilution) and were incubated at $30{ }^{\circ} \mathrm{C}$ in a shaking incubator $(130 \mathrm{rpm})$ until an $\mathrm{OD}_{600}>6.0$ was reached. Then the temperature was reduced to $25{ }^{\circ} \mathrm{C}$ for $18 \mathrm{~h}$ more. Cells were harvested by centrifugation, resuspended in Tris- $\mathrm{HCl}$ buffer (50 mM, pH 7.5; $0.5 \mathrm{M} \mathrm{NaCl}$ ), and disrupted by ultrasonication. After centrifugation, the enzymatic activity of the supernatant was compared using the DCIP assay.

Aspergillus niger cotransformation was carried out as previously described by Punt and van den Hondel [41], using the pAN52-CtCDH and pAB4-1 in a 10:1 ratio. Transformants were selected for uridine prototrophy on selective solid minimum medium (without uridine) and incubated for 10 days. In order to screen the best transformant for enzyme production in liquid medium, $50 \mathrm{~mL}$ of culture medium was inoculated with $2 \times 10^{6}$ spores $\mathrm{mL}^{-1}$ in a $250-\mathrm{mL}$ baffled flask. The culture was monitored for 14 days at $30{ }^{\circ} \mathrm{C}$ and $130 \mathrm{rpm}$. The $\mathrm{pH}$ was adjusted to 5.5 with $1 \mathrm{M}$ citric acid and activity was checked daily.

Trichoderma reesei transformation was performed as described [42] using uncut plasmid DNA. Transformants were streaked twice onto PDA plates that contained $50 \mu \mathrm{g} \mathrm{mL} \mathrm{m}^{-1}$ of hygromycin $\mathrm{B}$, and purified by plating conidiospores onto PDA plates with $0.1 \%$ Triton X-100 as colony restrictor. Candidate transformants were screened in shaking flasks $\left(160 \mathrm{rpm}, 28{ }^{\circ} \mathrm{C}\right)$ in a modified MAMedium ( $50 \mathrm{~mL}$ in a $250-\mathrm{mL}$ shaken flask) for 10 days. The $\mathrm{pH}$ was adjusted daily to 5.0 with $2 \mathrm{M} \mathrm{KOH}$. Culture supernatants were collected by filtration with Miracloth and used for enzymatic analysis.

\section{Production of recombinant $C t D H / C t C D H s$ in different systems}

An overnight seed culture of the E. coli transformant (selected from a LB plate with $100 \mu \mathrm{g} \mathrm{mL} \mathrm{m}^{-1}$ ampicillin) 
was inoculated at a 1:40 dilution into $6 \mathrm{~L}$ MagicMedia (which starts the expression of $\mathrm{CtDH}$ by autoinduction) with $100 \mu \mathrm{g} \mathrm{mL} \mathrm{m}^{-1}$ ampicillin in a 7-L glass vessel fermenter (MBR Bioreactor, Wetzikon, Switzerland). The initial cultivation temperature was $30{ }^{\circ} \mathrm{C}$, the variable airflow rate was around $6 \mathrm{~L} \mathrm{~min}^{-1}$, and the agitation was set to $500 \mathrm{rpm}$. After $6 \mathrm{~h}$, the cultivation temperature was changed to $25^{\circ} \mathrm{C}$. Samples were taken initially and after 3 , $6,11,24$ and $28 \mathrm{~h}$. Cells were collected by centrifugation and used to determine wet biomass. The pellet was resuspended in $50 \mathrm{mM}$ Tris- $\mathrm{HCl}$ buffer and disrupted by ultrasonication. The intracellular $\mathrm{CDH}$ activity and protein concentration were assayed after centrifugation. The corresponding specific activity of the crude extract was calculated from the volumetric activity of the crude extract divided by the specific activity of the purified enzyme.

Aspergillus niger fermentation was carried out in 7-L MBR fermenter, inoculating $8 \times 10^{9}$ spores in $4 \mathrm{~L}$ culture medium. The following set points were used: $\mathrm{pH}$ 5.5, $\mathrm{T}=30{ }^{\circ} \mathrm{C}$, Airflow $6 \mathrm{~L} \mathrm{~min}{ }^{-1}$. The $\mathrm{pH}$ was maintained using $2 \mathrm{M}$ citrate acid. Initial agitation speed was $350 \mathrm{rpm}$. At day 5 , agitation was increased to $600 \mathrm{rpm}$ and $0.5 \mathrm{~L}$ water was added to submerge the mycelium. Samples were taken daily and the $\mathrm{CDH}$ activity, protein and glucose concentration of the supernatant were measured.

Cultivation of T. reesei was performed in a Sixfors bioreactor (Infors HT, Bottmingen, Switzerland) with a working volume of $0.4 \mathrm{~L}$. Inoculum culture was pre-grown in $250 \mathrm{~mL}$ Erlenmeyer flasks on a rotary shaker $(160 \mathrm{rpm})$ at $28{ }^{\circ} \mathrm{C}$, containing $50 \mathrm{~mL}$ modified MA-medium. Pre-culture grown for $24 \mathrm{~h}$ was filtered, the biomass washed with sterile water and transferred into the fermenter. Operating conditions were: $\mathrm{pH} 5.0,28^{\circ} \mathrm{C}, 400 \mathrm{rpm}$ and $0.4 \mathrm{vvm}$ (volumes of air per volume of liquid per minute). Samples were taken daily and activity was measured.

Enzyme production with each expression system was repeated twice (biological duplicates). The expression of volumetric activity and protein concentration differed by less than $10 \%$ (data not shown). We only report the results of the fermentation from which we purified the enzyme. All measurements of volumetric activities and protein concentrations were performed three times (technical triplicates). Protein concentrations were determined by the Bradford method using a prefabricated assay from Bio-Rad Laboratories and bovine serum albumin (BSA) as the calibration standard [43]. Glucose concentrations were measured by D-glucose Assay Kit (Megazyme, Wicklow, Ireland).

\section{Purification of recombinant $C t D H / C t C D H s$ in different systems}

The $E$. coli fermentation broth was centrifuged at $4000 \times g$ for $10 \mathrm{~min}$ at $4{ }^{\circ} \mathrm{C}$, the pellets were suspended in $1.5 \mathrm{~L}$
Tris- $\mathrm{HCl}$ buffer $(50 \mathrm{mM}, \mathrm{pH} 7.5 ; 0.5 \mathrm{M} \mathrm{NaCl})$ and disrupted using a APV Rannie und Gaulin homogenizer. The crude extract obtained by centrifugation $(6000 \times g$, $30 \mathrm{~min}, 4{ }^{\circ} \mathrm{C}$ ) was loaded onto a HiTrap HP column (65 mL, GE Healthcare). The His-tagged $\mathrm{CtDH}$ was eluted by a linear gradient of imidazole $(5-500 \mathrm{mM})$ in Tris- $\mathrm{HCl}$ buffer $(50 \mathrm{mM}, \mathrm{pH} 7.5 ; 0.5 \mathrm{M} \mathrm{NaCl})$. Active fractions $(\sim 60 \mathrm{~mL})$ were pooled and desalted using a HiTrap Desalting Column. The enzyme solution was further purified and concentrated 10-fold using an ultrafiltration module (30-kDa cutoff, Sartorius Stedim, Germany).

The purification strategy for the supernatants of $A$. niger and T. reesei fermentations was similar as previously described [15]. The culture broth was clarified by filtration with Miracloth and centrifuged at $6000 \times g$ for $20 \mathrm{~min}$. Saturated ammonium sulfate solution was gently added to give a $20 \%$ saturation and particles were removed by centrifugation $\left(6000 \times g, 30 \mathrm{~min}, 4{ }^{\circ} \mathrm{C}\right)$. The clear supernatant was applied on a Phenyl FF hydrophobic column (70 mL, GE Healthcare) equilibrated with $50 \mathrm{mM}$ sodium acetate buffer $\mathrm{pH} 5.5$ containing $20 \%$ (saturation) ammonium sulfate. The proteins were then eluted by a linear gradient from 20 to $0 \%\left(\mathrm{NH}_{4}\right)_{2} \mathrm{SO}_{4}$ in the same buffer in 5 column volumes at a flow rate of $1 \mathrm{~mL} \mathrm{~min}^{-1}$. Absorbances at 280, 420 (haem $b$ ), and $450 \mathrm{~nm}$ (FAD) were measured online along with the conductivity values. Fractions were collected automatically and tested by the cyt $c$ activity assay. Active fractions were pooled and then diafiltered with sodium acetate buffer using an ultrafiltration module with a $10-\mathrm{kDa}$ cutoff until a conductivity of $2-3 \mathrm{mS} \mathrm{cm}{ }^{-1}$ was obtained. The partially deionized enzyme solution was loaded on a Q15-source anion exchange column $(19 \mathrm{~mL}$, GE Healthcare), previously equilibrated with $50 \mathrm{mM}$ sodium acetate buffer $\mathrm{pH}$ 5.5. Proteins were eluted by increasing the amount of elution buffer $(50 \mathrm{mM}$ sodium acetate buffer, pH 5.5, containing $500 \mathrm{mM} \mathrm{NaCl}$ ) linearly from 0 to $100 \%$ in 10 column volumes at a flow rate of $0.5 \mathrm{~mL} \mathrm{~min}{ }^{-1}$. Fractions containing $\mathrm{CDH}$ activity were pooled and concentrated by ultrafiltration through a polyether-sulfone membrane with a $10 \mathrm{kDa}$ molecular mass cutoff (Vivaflow crossflow cassette, Sartorius, Les Ulis, France). The purity and molecular weight of the recombinant enzymes were determined using SDS-PAGE.

\section{Electrophoretic analysis}

SDS-PAGE was carried out by using Mini-Protean TGX precast gels (Bio-Rad Laboratories, Austria) with a gradient of 4-15\% polyacrylamide. Proteins were visualized by Coomassie brilliant blue staining. The molecular mass under denaturating conditions was determined with a Precision Plus Protein Dual Color Standard (Bio-Rad 
Laboratories, Austria). All procedures were done according to the manufacturer's recommendations.

To estimate the degree of glycosylation, homogenous enzymes were treated with $\mathrm{N}$-glycosidase $\mathrm{F}$ (PNGase F) (New England BioLabs, Frankfurt, Germany), which cleaves the bond between N-Acetyl-glucosamine and Asparagine in $\mathrm{N}$-linked glycoproteins under denaturing conditions, according to the manufacturer's instructions. Reaction mixtures were incubated for $1 \mathrm{~h}$ at $37^{\circ} \mathrm{C}$ and analysed on SDS-PAGE gels.

\section{UV/Vis spectra and determination of FAD loading}

Spectra of homogeneously purified proteins were recorded from 700 to $250 \mathrm{~nm}$ at room temperature in both the oxidized and reduced states using a Hitachi U-3000 spectrophotometer (Hitachi, Tokyo, Japan). The purified proteins, which were in the oxidized state after purification, were diluted in $50 \mathrm{mM}$ sodium acetate buffer, $\mathrm{pH} 5.5$, to an absorbance at $280 \mathrm{~nm}$ of $\sim 1$ before recording a spectrum. The spectrum of the reduced enzyme was measured immediately after addition of a 100 -fold molar excess of cellobiose to the cuvette. The molar absorption coefficients at $280 \mathrm{~nm}$ for all proteins were calculated by using the mature amino acid sequence and the ProtParam program (http://web. expasy.org/protparam/). The calculated molar absorption coefficients of $C t \mathrm{DH}$ at $280 \mathrm{~nm}\left(\varepsilon_{280}=109 \mathrm{mM}^{-1} \mathrm{~cm}^{-1}\right)$ and $C t \mathrm{CDH}\left(\varepsilon_{280}=149 \mathrm{mM}^{-1} \mathrm{~cm}^{-1}\right)$ were used for the determination of the protein concentration. To assess the purity of the various $C D H$ preparations, the $R_{Z}$ values, defined by the ratio $A_{420} / A_{280}$, were calculated for each $\mathrm{CDH}$ in its oxidized state.

The FAD loading was determined according to a published protocol using trichloroacetic acid to release the non-covalently bound FAD cofactor from the protein by precipitation [26]. After precipitation, the $\mathrm{pH}$ of the solution was carefully titrated with grains of solid sodium carbonate to a $\mathrm{pH}$ of $6-7$. Then a spectrum was taken immediately to quantify the amount of FAD in the solution. The amount FAD was calculated using the molar absorption coefficient for free FAD $\left(\varepsilon_{450}=11.3 \mathrm{mM}^{-1} \mathrm{~cm}^{-1}\right)$.

\section{Enzyme activity assays}

Enzyme activity was assayed spectrophotometrically using cyt $c\left(\varepsilon_{550}=19.6 \mathrm{mM}^{-1} \mathrm{~cm}^{-1}\right)$ as electron acceptor for intact CDH or DCIP $\left(\varepsilon_{550}=6.8 \mathrm{mM}^{-1} \mathrm{~cm}^{-1}\right)$ as an electron acceptor for both the intact holoenzyme and the dehydrogenase domain. The activities were determined by monitoring the reduction of $300 \mu \mathrm{M}$ 2,6-dichlorophenol indophenol (DCIP) in $50 \mathrm{mM}$ sodium acetate buffer (pH 5.5) containing $30 \mathrm{mM}$ lactose and $4 \mathrm{mM}$ of sodium fluoride (sodium fluoride was used as a laccase inhibitor). The cyt $c$-based assay contained $50 \mathrm{mM}$ Tris- $\mathrm{HCl}$ buffer,
$\mathrm{pH} 7.5,20 \mu \mathrm{M}$ cyt $c$ and $30 \mathrm{mM}$ lactose. The reaction was monitored for $180 \mathrm{~s}$ at $30^{\circ} \mathrm{C}$ in a Lambda $35 \mathrm{UV}-$ Visible spectrophotometer featuring a temperature-controlled 8-cell changer (Perkin Elmer, Massachusetts, USA). Enzyme activity was defined as the amount of enzyme that oxidizes $1 \mu \mathrm{mol}$ of the electron acceptor per minute under the assay conditions.

\section{Steady-state-kinetic measurements}

The kinetic parameters were determined for cellobiose oxidation measured at $30{ }^{\circ} \mathrm{C}$ in $100 \mathrm{mM}$ McIlvaine buffer pH 5.5 using DCIP or pH 7.5 using cyt $c$. The concentration of cellobiose ranged from $10 \mu \mathrm{M}$ to $5 \mathrm{mM}$ with both electron acceptors (DCIP and cyt $c$ ). Triplicates were run to ensure reliable kinetic parameter determination. Catalytic constants were calculated using nonlinear least squares regression by fitting the observed data to the Michaelis-Menten equation (Sigma Plot 12.0, Systat Software). Protein concentration was determined by measuring absorbance at $280 \mathrm{~nm}$ (A280).

\section{Thermal stability measurements}

ThermoFAD assays were performed according to Forneris et al. [27] and Reich et al. [44]. This method is based on the intrinsic fluorescence of the flavin cofactor of the flavoproteins and the fluorescence of the flavin cofactor is quenched by the protein environment. $25 \mu \mathrm{L}$ of enzyme solution $(15,7.5$ and $1.5 \mu \mathrm{M})$ was heated from 30 to $85{ }^{\circ} \mathrm{C}$ in increments of $1{ }^{\circ} \mathrm{C}$ per min using a MyiQ Real-Time PCR cycler (Bio-Rad Laboratories, California, USA) using an excitation wavelength range between 470 and $500 \mathrm{~nm}$ and an SYBR Green fluorescence emission filter (523-543), which falls within the same fluorescence range as the isoalloxazine ring of the FAD (470-570). The $T_{\mathrm{m}}$ values were obtained as the maximum of the first derivative of the sigmoid curves and the reported $T_{\mathrm{m}}$ values are the mean value of 12 independent experiments (triplicate for each enzyme concentration).

Alternatively, unfolding of the intact $\mathrm{CDH}$ was monitored by following the intrinsic tryptophan fluorescence upon heating [45]. Tryptophan is located on both CYT and DH (from 21 Trp residues 5 are located in CYT and 16 are located in DH). Experiments were performed in a temperature controlled Cary Eclipse fluorescence spectrophotometer (Agilent Technologies, California, USA) at a total volume of $2 \mathrm{~mL}$ and $\mathrm{CDH}$ or $\mathrm{DH}$ concentration of $1.5 \mu \mathrm{M}$. Cuvettes were stirred throughout the experiment. A heat ramp from 30 to $85^{\circ} \mathrm{C}$ was applied at a rate of $1{ }^{\circ} \mathrm{C}$ per min. The excitation wavelength was $279 \mathrm{~nm}$; the emission was recorded at 320 and $360 \mathrm{~nm}$. The $T_{\mathrm{m}}$ was determined by fitting the tryptophan fluorescence emission ratio of $360-320 \mathrm{~nm}$ to a sigmoidal function. All experiments were performed in triplicates. 


\section{Additional file}

Additional file 1: Table S1. Purification schemes of recombinant $\mathrm{CtDH} / \mathrm{CtCDH}$. Table S2. Comparison of recombinant DH domain and intact $\mathrm{CDH}$ s from literatures. Figure S1. SDS-PAGE of recombinant $\mathrm{CtDH}$ expressed in E. coli. Figure S2. Thermostability of $\mathrm{CtDH} / \mathrm{CtCDHs}$ measured by the tryptophan fluorescence (A-D) and the ThermoFAD method (E-H).

\section{Abbreviations}

$\mathrm{CDH}$ : cellobiose dehydrogenase; $\mathrm{CtCDH}$ : $\mathrm{CDH}$ from Corynascus thermophilus; $\mathrm{CtDH}$ : dehydrogenase domain of $\mathrm{CtCDH}$; $\mathrm{CYT}$ : cytochrome domain of $\mathrm{CDH}$; cyt c: cytochrome c; DCIP: 2,6-dichloroindophenol; DET: direct electron transfer; MET: mediated electron transfer; $\mathrm{DH}$ : dehydrogenase domain of $\mathrm{CDH}$; FAD: flavin adenine dinucleotide; IET: intramolecular electron transfer; LPMO: Iytic polysaccharide monooxygenase.

\section{Authors' contributions}

SM planned and performed the majority of experiments, analyzed the data and wrote the manuscript. RL coordinated the study and revised the manuscript. MP performed part of the screening and production of $\mathrm{CtCDH}$ in A. niger. DK designed the thermostability experiments, performed part of the experiments and data processing. FP and ER performed the transformation and screening of $\mathrm{CtCDH}$ in A. niger. LK and BS performed part of the transformation of $\mathrm{CtCDH}$ in T. reesei. All authors read and approved the final manuscript.

\section{Author details}

1 Department of Food Sciences and Technology, Vienna Institute of Biotechnology, BOKU-University of Natural Resources and Life Sciences, Vienna, Austria. ${ }^{2}$ UMR BDR, INRA, ENVA, Université Paris Saclay, 78350 Jouy en Josas, France. ${ }^{3}$ Research Area Biochemical Technology, Institute of Chemical Engineering, TU Wien, Gumpendorferstrasse 1a, Vienna, Austria. ${ }^{4}$ Aix Marseille Université, INRA, BBF (Biodiversité et Biotechnologie Fongiques), Marseille, France.

\section{Acknowledgements}

We thank Nenad Mardetko, Qingying Yu, Tanja Lesic, Stephen Nagle and Diarmaid de Barra for technical assistance.

\section{Competing interests}

The authors declare that they have no competing interests.

\section{Availability of data and materials}

The datasets supporting the conclusions of this article are included within the article and its Additional file 1.

\section{Funding}

Financial support from the European Commission is gratefully acknowledged (project BIOENERGY FP7-PEOPLE-2013-ITN-607793).

Received: 2 December 2016 Accepted: 25 February 2017

Published online: 28 February 2017

\section{References}

1. Cameron MD, Aust SD. Cellobiose dehydrogenase-an extracellular fungal flavocytochrome. Enzyme Microb Technol. 2001;28:129-38.

2. Correa TLR, dos Santos LV, Pereira GAG. AA9 and AA10: from enigmatic to essential enzymes. Appl Microbiol Biotechnol. 2016;100:9-16.

3. Hemsworth GR, Johnston EM, Davies GJ, Walton PH. Lytic polysaccharide monooxygenases in biomass conversion. Trends Biotechnol. 2015:33:747-61.

4. Phillips CM, Beeson WT IV, Cate JH, Marletta MA. Cellobiose dehydrogenase and a copper-dependent polysaccharide monooxygenase potentiate cellulose degradation by Neurospora crassa. ACS Chem Biol. 2011;6:1399-406
5. Beeson WT, Vu W, Span EA, Phillips CM, Marletta MA. Cellulose deg radation by polysaccharide monooxygenases. Annu Rev Biochem. 2015:84:923-46.

6. Zamocky M, Hallberg M, Ludwig R, Divne C, Haltrich D. Ancestral gene fusion in cellobiose dehydrogenases reflects a specific evolution of GMC oxidoreductases in fungi. Gene. 2004;338:1-14.

7. Tan TC, Kracher D, Gandini R, Sygmund C, Kittl R, Haltrich D, Hallberg BM, Ludwig R, Divne C. Structural basis for cellobiose dehydrogenase action during oxidative cellulose degradation. Nat Commun. 2015:6:7542.

8. Zhang R, Fan Z, Kasuga T. Expression of cellobiose dehydrogenase from Neurospora crassa in Pichia pastoris and its purification and characterization. Protein Expr Purif. 2011;75:63-9.

9. Harreither W, Sygmund C, Augustin M, Narciso M, Rabinovich ML, Gorton L, Haltrich D, Ludwig R. Catalytic properties and classification of cellobiose dehydrogenases from ascomycetes. Appl Environ Microbiol. 2011:77:1804-15.

10. Felice AK, Sygmund C, Harreither W, Kittl R, Gorton L, Ludwig R. Substrate specificity and interferences of a direct-electron-transfer-based glucose biosensor. J Diabetes Sci Technol. 2013;7:669-77.

11. Stoica L, Lindgren-Sjolander A, Ruzgas T, Gorton L. Biosensor based on cellobiose dehydrogenase for detection of catecholamines. Anal Chem. 2004;76:4690-6.

12. Ludwig R, Ortiz R, Schulz C, Harreither W, Sygmund C, Gorton L. Cellobiose dehydrogenase modified electrodes: advances by materials science and biochemical engineering. Anal Bioanal Chem. 2013;405:3637-58

13. Ludwig R, Salamon A, Varga J, Zamocky M, Peterbauer CK, Kulbe KD, Haltrich D. Characterisation of cellobiose dehydrogenases from the white-rot fungi Trametes pubescens and Trametes villosa. Appl Microbiol Biotechnol. 2004:64:213-22.

14. Bey M, Berrin JG, Poidevin L, Sigoillot JC. Heterologous expression of Pycnoporus cinnabarinus cellobiose dehydrogenase in Pichia pastoris and involvement in saccharification processes. Microb Cell Fact. 2011;10:113.

15. Harreither W, Felice AK, Paukner R, Gorton L, Ludwig R, Sygmund C. Recombinantly produced cellobiose dehydrogenase from Corynascus thermophilus for glucose biosensors and biofuel cells. Biotechnol J. 2012;7:1359-66.

16. Turbe-Doan A, Arfi Y, Record E, Estrada-Alvarado I, Levasseur A. Heterologous production of cellobiose dehydrogenases from the basidiomycete Coprinopsis cinerea and the ascomycete Podospora anserina and their effect on saccharification of wheat straw. Appl Microbiol Biotechnol. 2013:97:4873-85.

17. Zamocky M, Ludwig R, Peterbauer C, Hallberg BM, Divne C, Nicholls P, Haltrich D. Cellobiose dehydrogenase-a flavocytochrome from wooddegrading, phytopathogenic and saprotropic fungi. Curr Protein Pept Sci. 2006;7:255-80

18. Ferri S, Sode K. Functional expression of Phanerochaete chrysosporium cellobiose dehydrogenase flavin domain in Escherichia coli. Biotechnol Lett. 2010:32:855-9.

19. Yoshida M, Ohira T, Igarashi K, Nagasawa H, Aida K, Hallberg BM, Divne C, Nishino T, Samejima M. Production and characterization of recombinant Phanerochaete chrysosporium cellobiose dehydrogenase in the methylotrophic yeast Pichia pastoris. Biosci Biotechnol Biochem. 2001;65:2050-7.

20. Zamocky M, Schumann C, Sygmund C, O'Callaghan J, Dobson AD, Ludwig R, Ludwig R, Haltrich D, Peterbauer CK. Cloning, sequence analysis and heterologous expression in Pichia pastoris of a gene encoding a thermostable cellobiose dehydrogenase from Myriococcum thermophilum. Protein Expr Purif. 2008;59:258-65.

21. Sygmund C, Kracher D, Scheiblbrandner S, Zahma K, Felice AK, Harreither W, Kittl R, Ludwig R. Characterization of the two Neurospora Crassa cellobiose dehydrogenases and their connection to oxidative cellulose degradation. Appl Environ Microbiol. 2012;78:6161-71.

22. Liu L, Yang H, Shin H, Chen R, Li J, Du G, Chen J. How to achieve high-leve expression of microbial enzymes: strategies and perspectives. Bioengineered. 2013;4:212-23.

23. Punt PJ, van Biezen $\mathrm{N}$, Conesa A, Albers A, Mangnus J, van den Hondel C. Filamentous fungi as cell factories for heterologous protein production. Trends Biotechnol. 2002;20(5):200-6.

24. Langston JA, Brown K, Xu F, Borch K, Garner A, Sweeney MD. Cloning, expression, and characterization of a cellobiose dehydrogenase from 
Thielavia terrestris induced under cellulose growth conditions. Biochim Biophys Acta. 2012;1824:802-12.

25. Wang M, Lu X. Exploring the Synergy between cellobiose dehydrogenase from Phanerochaete chrysosporium and cellulase from Trichoderma reesei. Front Microbiol. 2016;7:620.

26. Macheroux P. UV-visible spectroscopy as a tool to study flavoproteins. Methods Mol Biol. 1999;131:1-7.

27. Forneris F, Orru R, Bonivento D, Chiarelli LR, Mattevi A. ThermoFAD, a Thermofluor-adapted flavin ad hoc detection system for protein folding and ligand binding. FEBS J. 2009;276:2833-40.

28. Schou C, Christensen MH, Schulein M. Characterization of a cellobiose dehydrogenase from Humicola insolens. Biochem J. 1998;330:565-71.

29. Baminger U, Subramaniam SS, Renganathan V, Haltrich D. Purification and characterization of cellobiose dehydrogenase from the plant pathogen Sclerotium (Athelia) rolfsii. Appl Environ Microbiol. 2001;67:1766-74.

30. Lee $\mathrm{CW}$, Wang $\mathrm{HJ}$, Hwang JK, Tseng CP. Protein thermal stability enhancement by designing salt bridges: a combined computational and experimental study. PLoS ONE. 2014;9:e112751.

31. Kumar S, Tsai CJ, Nussinov R. Factors enhancing protein thermostability. Protein Eng. 2000;13:179-91.

32. Li W, Zhou X, Lu P. Structural features of thermozymes. Biotechnol Adv. 2005:23:271-81.

33. Shirke AN, Su A, Jones JA, Butterfoss GL, Koffas MA, Kim JR, Gross RA. Comparative thermal inactivation analysis of Aspergillus oryzae and Thiellavia terrestris cutinase: role of glycosylation. Biotechnol Bioeng. 2016. doi:10.1002/bit.26052

34. Gordon CL, Khalaj V, Ram AF, Archer DB, Brookman JL, Trinci AP, Jeenes DJ, Doonan JH, Wells B, Punt PJ, van den Hondel CA, Robson GD. Glucoamylase:green fluorescent protein fusions to monitor protein secretion in Aspergillus niger. Microbiology. 2000;146(Pt 2):415-26.

35. Stricker AR, Grosstessner-Hain K, Wurleitner E, Mach RL. Xyr1 (xylanase regulator 1 ) regulates both the hydrolytic enzyme system and D-xylose metabolism in Hypocrea jecorina. Eukaryot Cell. 2006;5:2128-37.
36. Vaheri M, Leisola M, Kauppinen V. Transglycosylation products of cellulase system of Trichoderma reesei. Biotechnol Lett. 1979;1:41-6.

37. Conesa A, van den Hondel CA, Punt PJ. Studies on the production of fungal peroxidases in Aspergillus niger. Appl Environ Microbiol. 2000;66:3016-23.

38. van Hartingsveldt W, Mattern IE, van Zeijl $C M$, Pouwels $\mathrm{PH}$, van den Hondel CA. Development of a homologous transformation system for Aspergillus niger based on the pyrG gene. Mol Gen Genet. 1987;206:71-5.

39. Uzbas F, Sezerman U, Hartl L, Kubicek CP, Seiboth B. A homologous production system for Trichoderma reesei secreted proteins in a cellulase-free background. Appl Microbiol Biotechnol. 2012;93:1601-8.

40. Piumi F, Levasseur A, Navarro D, Zhou S, Mathieu Y, Ropartz D, Ludwig R, Faulds CB, Record E. A novel glucose dehydrogenase from the white-rot fungus Pycnoporus cinnabarinus: production in Aspergillus niger and physicochemical characterization of the recombinant enzyme. Appl Microbiol Biotechnol. 2014;98:10105-18.

41. Punt PJ, van den Hondel CA. Transformation of filamentous fungi based on hygromycin B and phleomycin resistance markers. Methods Enzymol. 1992;216:447-57.

42. Gruber F, Visser J, Kubicek C, De Graaff $L$. The development of a heterologous transformation system for the cellulolytic fungus Trichoderma reesei based on a pyrG-negative mutant strain. Curr Genom. 1990;18:71-6.

43. Bradford MM. A rapid and sensitive method for the quantitation of microgram quantities of protein utilizing the principle of protein-dye binding. Anal Biochem. 1976;72:248-54.

44. Reich S, Kress N, Nestl BM, Hauer B. Variations in the stability of NCR ene reductase by rational enzyme loop modulation. J Struct Biol. 2014;185:228-33.

45. Permyakov EA, Burstein EA. Some aspects of studies of thermal transitions in protein by means of their intrinsic fluorescence. Biophys Chem. 1984;19:265-71.

\section{Submit your next manuscript to BioMed Central and we will help you at every step:}

- We accept pre-submission inquiries

- Our selector tool helps you to find the most relevant journal

- We provide round the clock customer support

- Convenient online submission

- Thorough peer review

- Inclusion in PubMed and all major indexing services

- Maximum visibility for your research

Submit your manuscript at www.biomedcentral.com/submit
() Biomed Central 